\title{
11. Tackling cartels: lessons for making and entrenching reform
}

\author{
William E. Kovacic
}

My background is teaching law and my natural habitat is the university, but for nine of the past 10 years I have been tackling national and international cartels and seeing theory meet practice at a federal institution, the Federal Trade Commission. For me, the deepest education in that process has been realising how hard it is not only to get seemingly straightforward things done, but also to make certain that changes or adjustments in a policy stick. This chapter will focus on those experiences.

I think often of the work of my historian colleague Ronald Spector, who writes about organisations and public services with a particular focus on defence organisations. In his book At War at Sea (2001), he analyses the desperate efforts of the Allies to develop effective convoying systems in the beginning of the Battle of the Atlantic in World War II, and out of absolute necessity they were pressed to put very junior and inexperienced people into positions of command. In the book, Spector cites the experience of a young Canadian officer who had never been to sea, only to find himself commanding a Corvette that is weaving dangerously through the convoy. Observing the situation, a senior British officer of a destroyer sent a blinkered message to him: 'What do you think you're doing?' And the answer that came back from the Canadian officer was: 'Learning a lot.'

To me, one of the greatest elements of 'learning a lot' has been to see how difficult it is to make reforms stick. In this chapter, I wish to discuss a reform that has been seen largely as a policy success: the development of a global consensus favouring substantial attacks on cartel behaviour. I will first cover some recurring phenomena that are formative preconditions for making reforms stick, then discuss a change inside the anti-trust system that involves the ramping up of criminal enforcement against cartels. I will next discuss the larger set of policy relationships that determines whether or not reforms taken inside a single discipline are effective over time. Finally, I will explore the individual implications of this for larger public-policy changes. 


\section{Formative preconditions of which policy makers ought to be aware}

There are three recurring phenomena that determine whether reforms stick. The first of these formative preconditions is the fact that it is rarely the case that a single element of policy is absolutely independent of others. This suggests that if we were all to map out the policy space in which our institutions operate, we will find they share boundaries with a host of other government agencies, whose decisions basically bring us into what is an interdependent equation with different variables. A change in one will send ripples throughout the system, and interest other institutions.

This is the 'policy archipelago': a web of interconnected reefs and islands. It exists across disciplines, and across jurisdictional boundaries. And needless to say these relationships are not always amicable and agreeable across agencies.

There is a famous story told about Curtis LeMay during the time he was the head of the Strategic Air Command of the US Air Force (1948-57). He was getting a briefing from a junior Air Force officer, who referred to the Soviet Union as an enemy. LeMay interrupted and said: 'No! No! No! The Soviet Union is an adversary. Our enemy is the United States Navy.' As this quote illustrates, in many instances, we often find enormous amounts of tension across public institutions, where you might assume from a distance that because they are part of the same public service architecture they will have shared interests.

The second formative precondition is that regulated entities that are the subjects of reform, especially those whose behaviour is being constrained, are remarkably resilient and adaptive. They are geographically mobile in many instances. They will move to different jurisdictions within a country, or across borders, that do not have the same controls. They are highly adaptive in pursuing their own objectives through other means, so that if we were to impose an effective regulatory reform with respect to one dimension of their behaviour, they do not then surrender, throw up their hands, and say 'I give up'; they try to circumvent the new rules.

This feature has to be seen as a version of an 'arms race' in which any single adjustment by the public-sector body is going to be matched with counterstrategies by the other institutions. Hence, in any thinking about introducing significant reforms, a necessary element of the policy-development process must be to ask: 'what is going to be their next move?' They are not going to stand still and do exactly what we hope they might do.

And last, there is a tremendous benefit to public institutions of economic and historical precedence, which can be assembled only through a profound 
process of retrospection. The evaluation of outcomes, and the learning from the experience base, can happen only if there is enough institutional memory, continuity, and commitment to do this kind of difficult assessment inside the body.

\section{Enforcement against antitrust behaviour}

The recent development of a widespread anti-cartel norm across society has been one of the most striking elements of public policy experienced throughout the field of competition law. Take an example from the beginning of the US experience with competition law-now 120 years old - that illustrates the dramatic evolution in the form of criminal sanctions brought to bear on producer cartels that covertly seek to reduce output at increased price.

For such wrongdoers, the basic fine level in 1890 was $\$ 5000$ - a little bit more money than it is now, and the offence was a misdemeanour, which is a relatively light-handed criminal offence. It stayed that way for 65 years. In 1955, Congress took the bold step of raising the maximum fine to $\$ 50000$, but left the offence level in place. That might have seemed quaint in 1955, but by 1974 it was a laughable deterrent. In other words, imagine going to a significant price-fixing organisation such as Archer Daniels in Midland and saying 'that will be a $\$ 50$ 000 fine, please'. They would reach into their pockets and say: 'I think I've got that right here. See you the next time, for the next defence.' In 1974, the offence was again boosted, to a \$1 million maximum fine - still quaint-but it was changed to a felony, which is a much more serious offence, with three years' maximum prison term for individuals.

In 1987, the law was ramped up further-doubling the fine and with the possibility of recovering the proceeds. Effectively, it permitted multi-hundred million-dollar recoveries in individual cases. In 1990, it became a \$10 million fine per offence, plus allowing higher damages to be awarded by the courts ('double the loss' for violators, 'double the gain' for victims). And in 2004 the law became a $\$ 100$ million maximum for each offence, as well as 'double the loss, double the gain', and a felony with a maximum prison sentence now of 10 years. That is what criminals now get for bank robbery. Price fixing in the United States is now treated as an extremely serious criminal offence, with comparable civil and criminal trends taking place elsewhere. This represents a great policymaking success.

But, stepping back, there are equilibrating tendencies that have to be taken into account when assessing progress and asking 'will things stick'? As we raise sanctions and compensation in the legal system, and as the ante is upped, a couple of things happen. We have to convince courts and juries that it is 
worth taking away the freedom of the violating individuals - and this was a big cultural shock when we go back to 1974, and the US system became much more serious minded about doing this.

First, we had to convince juries that price fixing was a serious offence worthy of criminal punishment; but juries were not accustomed to defining 'anticompetitive' behaviour in this way. Crimes against individuals involving harm to body and property - these were thought of as serious offences. In antitrust cases, the accused person sitting in the courtroom was someone typically wearing a suit and white collar-someone who looked like your uncle or your father. And what was the offence? Well, price fixing. What was that? Who cared? In the eyes of many juries, this was nowhere as serious as entering a bank with a ski mask and a revolver. Moreover, the moment we started to bring forward these cases, the firms in question quickly adapted and used counter-strategies.

The effectiveness of the US legal-enforcement practices depended on addressing both of these concerns: jury attitudes and counter-strategies by the accused. And there were a number of very successful strategies devised to tackle these concerns. US prosecutors - and often their counterparts in many other counties - realised that we had to establish a norm that accepted criminal punishment as routine for antitrust violations. So what did they do? Well, they built on an academic consensus that cartels were almost invariably harmful, and carefully picked the right cases to prosecute at the beginning. And what were the first cases for which we pushed for more powerful sanctions in the United States? They involved public procurement, and in particular public procurement for such basics as milk, involving such things as bid rigging against school authorities. So what was the case? Perhaps the person accused looked like a sweet uncle, but here is what he had done. He had artificially raised the price of the milk the children were meant to consume. This meant for our popular campaign that these dear little children were going to go hungry in school, because the school district could not afford to pay for the milk. As prosecutors, we were building public outrage.

Other cases involved price fixing for municipal supplies. So, for instance, the terrible roads that motorists were driving on remained in poor condition because the local municipal authority tasked with maintaining them could not afford to because the suppliers set the price for the concrete and the paving services. These price fixers might not have been wearing ski masks and waving revolvers about, but they were nevertheless thieving from the public purse. And, it was argued, as law-abiding taxpayers, the citizenry should not feel bad about taking their freedom away.

The development of those early procurement cases created a social expectation and community acceptance of the idea that price fixing was a serious offence. This 
was a deliberate, careful strategy that resulted in the successful implementation of the program. In many respects, the procurement-first strategy changed social attitudes such that people began to accept such prosecutions as a useful application of serious, powerful sanctions.

A second key element involved examining closely the empirical data that were being uncovered by the prosecutions. What one often finds in cases where public policies are inherently interdependent is that the root cause of some sanctionable behaviour in one sector lies in some other collateral area of decision making. And so it was with many of the prosecution cases taken up against bid rigging and anti-competitive offences.

What was discovered? We found that one of the main contributory causes of cartels were restrictions that require public procurement authorities to buy only from domestic sources. In the commercial world, if you want to draw a bullseye on the back of public purchasing authorities, make sure that their domestic content restrictions are extremely onerous. Consider the example of a successful prosecution of a company that sold frozen fish to the Department of Defence. What soon became clear was that there were only four firms able to supply such fish, and that there had been only four firms for about 30 years. Why was this? We found that there was an absolute prohibition on buying frozen fish from companies outside the United States, such as in Canada, Iceland and the United Kingdom. If we had allowed firms from these other countries to bid for these public contracts, the United States would probably have been covered with frozen fish up to a depth of about $20 \mathrm{~m}$, shore to shore. But by limiting the market to the US producers, we did them a great favour. They knew that no entry of other suppliers was permissible. And they knew that every time, in every procurement, these four US companies would confront each other again and again. So they got to know each other very well and colluded on price. In this way, by imposing the 'buy-American' requirements, the US Government did a great favour to facilitate cartels.

Similarly, in markets where foreign suppliers were not excluded, it soon became apparent that existing cartel members resorted to anti-dumping processes to try to keep these foreign suppliers from lucrative procurements. In effect, national and international trade rules and conventions were a great ally of cartel participants. Moreover, public procurement procedures, for example, required all bids from suppliers to be laid out on a table for all to see. It was a basic requirement that in an open tendering process, the sealed bids of all of the bidders are subsequently disclosed for transparency and scrutiny purposes. But what occurred in many instances was that there was a rush from participants to come to the front of the room to look at the table. Why were they so interested? 
If cartel participants were part of a bid-rigging scheme, it was a great way to establish whether or not their counterparts did what they promised to do. And it was a perfect way to detect deviations.

Another consequence of this international situation was that cartel firms that were getting hammered in North America simply decided to put together these cartels in other countries that did not view such behaviour as a serious offence. Firms could go from jurisdiction to jurisdiction selecting those that simply did not care, re-establishing their cartels without fear of challenge. For prosecutors and antitrust regulators, if we looked carefully at our experience base, we knew where these counter-strategies and pressures were coming from. It also gave us insights into how other public policies had to be changed inside North America and elsewhere in order to get a good solution.

We also observed that another way in which price-fixing businesses responded was to seek substitutes. Executives of firms soon realised that if they formed a private agreement with their counterparts, they risked going to prison. But if they could get public agencies and legislators to form the cartel for them, and it became mandatory, then the government agencies would in a sense unwittingly enforce the cartels on their behalf. Consequently, firms observed two optionsone that said 'go to jail', the other that said 'great success awaits you through manipulating public policy' — and they simply moved their strategies from one to the other. An example that comes to mind involved state legislation that forbids in many instances sales of wine on the Internet across state boundaries. The 'public policy' justification for such restrictions is that Internet trading would be likely to promote underage drinking, so it has to be banned. Now, each of these states that adopted the ban still allows consumers to use the Internet to buy wine from vineyards produced inside the state, but not across state borders. It is hard to imagine that there is any empirical evidence showing that drinking wine from within the state produces less drunkenness than drinking wine from outside the state! The regulation is premised on a fallacious rationale and done to stymie competition.

Who are the beneficiaries in this case? What was the public interest or publicsafety issue at stake? The public issue at stake was the income of the producers inside states. And many states acquiesced in this kind of legislation. Likewise, states have also misused their regulatory apparatus in other ways to prevent competition, such as by using land-use controls and challenges to new store openings to keep out external entrances. 


\section{The broader policy consequences}

So, it is clear from where I stand that the would-be cartel members never give up - they just adapt their strategies. Any single reform initiative aimed at improving the effectiveness of the antitrust law enforcement could easily be negated by these counter-strategies. What does this imply for substantial policy reform over time? What does the individual agency have to do? First, it has to foresee dynamic readjustments by firms, whether they are related to environmental policy, labour policy, competition policy or whatever else. The economic actors so affected will adapt and readjust. This creates an imperative for the public agency to think about how that adaptation might go on and, by means of ex-post evaluation, to observe how it is actually taking place.

The individual agency must commit to the process of looking back at actual experience, and asking: 'How are we going? Are reforms working? What are we learning from what we are seeing? And, is there some pathology that resides in some other collateral area of policy making that still needs to be fixed?' Otherwise, as policy makers, we are basically left picking the tops off weeds after they come out of the ground, and not getting to the roots to fix the real problems. This self-reflection can be done in part only through such internal diagnosis and examination. It will also involve examining connections to the larger world of policy development, once one sees the interdependencies and linkages. Such a situation results in effective advocacy before other public institutions, linked to public agencies with shared interests.

In the United States, we have found in the Federal Trade Commission that, as a federal agency, we have had to form cooperative relationships with state governments to keep them focused on the ongoing need for competition reform and ensure they act as the 'coast watchers'. We know that many would-be cartel firms are now going to state capitals to lobby for the adoption of legislation they hope will override other competition-policy commands. In return, through developing cooperative alliances with state government agencies, we hope to be able to persuade their legislatures not to adopt such measures, pointing out if they do the costs to economic efficiency. We have to be continual advocates. And, in mounting our advocacy, it is also important to draw upon the knowledge we have acquired and the types of economic precedence with which we have experience. Similarly, at the Federal Trade Commission, we have striven to build solid relationships with procurement officials across the jurisdictions in order to prevent them from becoming inevitable targets of effective cartels. In particular, during the recent stimulus program in the context of the global financial crisis, there was a dedicated effort to provide this kind of support and guidance. 
So, to conclude these reflections, in many respects the key element to making reforms effective and sustainable in the longer term comes down to how they were conceived initially and calibrated over time. Reform adjustments made within a single frame of reference (a paradigm, academic discipline, an agency 'mind-set') might not always be the most effective unless examined in a larger context of interactions with other areas of public policy. Moreover, perhaps the most important element of this diagnostic process is to undertake a dedicated effort to examine one's own patterns of experience - in short, the painful process of asking how and why things have worked or not worked. We need to go back and ask in a deep and meaningful way how and why things have turned out the way they have.

As a final reflection, one of my colleagues at George Washington University has an insightful sign on his office wall. It says: 'It's what you learn after you know it all that really counts.' We cannot beat experience, expertise, diagnosis and, of course, ongoing learning - that is the only way we will continue 'learning a lot'.

\section{Reference}

Spector, R. H. 2001, At War at Sea: Sailors and naval combat in the twentieth century, Viking Press, New York. 